\title{
Nuclear factor-кB inhibitor Bay11-7082 inhibits gastric cancer cell proliferation by inhibiting Gli1 expression
}

\author{
YAN YAN $^{1 *}$, HEYA QIAN $^{2 *}$, YING CAO $^{1}$ and TAO $\mathrm{ZHU}^{3}$ \\ Departments of ${ }^{1}$ Pharmacology, ${ }^{2}$ Oncology and ${ }^{3}$ Laboratory, The Affiliated Zhangjiagang \\ Hospital of Soochow University, Zhangjiagang, Jiangsu 215600, P.R. China
}

Received July 27, 2020; Accepted January 28, 2021

DOI: $10.3892 / \mathrm{ol} .2021 .12562$

\begin{abstract}
Dysregulated nuclear factor (NF)- $\kappa \mathrm{B}$ signaling pathway is involved in gastric carcinogenesis. The present study aimed to investigate the antitumor effects of the $\mathrm{NF}-\kappa \mathrm{B}$ inhibitor, Bay11-7082, on gastric cancer (GC) and elucidate its underlying molecular mechanisms. The MTT assay was performed to assess the effects of Bay11-7082 on the proliferation of HGC27 and MKN45 gastric cancer cells. In addition, the Transwell and wound healing assays were performed to determine cell migration and invasion, respectively. Reverse transcription-quantitative PCR and western blot analyses were performed to detect the mRNA and protein expression levels of the target genes. The results demonstrated that the half-maximal inhibitory concentration $\left(\mathrm{IC}_{50}\right)$ of Bay11-7082 in HGC27 cells was 24.88, 6.72 and 4.23 $\mathrm{nM}$ at 24, 48 and $72 \mathrm{~h}$, respectively. Furthermore, the $\mathrm{IC}_{50}$ of Bay11-7082 in MKN45 cells was 29.11, 11.22 and $5.88 \mathrm{nM}$ at 24, 48 and $72 \mathrm{~h}$, respectively. Treatment with Bay11-7082 significantly suppressed the cell migratory and invasive abilities compared with the control group. Notably, Bay11-7082 suppressed GLI Family Zinc Finger 1 (Gli1) mRNA and protein expression levels. Taken together, the results of the present study demonstrated that Bay11-7082 inhibited GC cell proliferation, at least in part through inhibition of Gli1.
\end{abstract}

Correspondence to: Dr Ying Cao, Department of Pharmacology, The Affiliated Zhangjiagang Hospital of Soochow University, 68 Jiyang West Road, Zhangjiagang, Jiangsu 215600, P.R. China E-mail: caoyaoshi@126.com

Dr Tao Zhu, Department of Laboratory, The Affiliated Zhangjiagang Hospital of Soochow University, 68 Jiyang West Road, Zhangjiagang, Jiangsu 215600, P.R. China

E-mail: tzhuyzu@163.com

*Contributed equally

Key words: nuclear factor- $\kappa \mathrm{B}$ inhibitor, Bay11-7082, Gli1, gastric cancer, cell migration

\section{Introduction}

Gastric cancer (GC) is the fourth leading cause of cancer-associated mortality worldwide, and its poor prognosis represents a major challenge in the clinical setting, although the incidence of GC has declined in developing countries due to the successful reduction of $H$. pylori infection (1-3). Approximately half of all patients with gastric tumors are diagnosed at an advanced stage in western countries (4), when palliative chemotherapies may be the only therapeutic option $(5,6)$. In addition, multiple treatments have not only failed to improve the outcomes of GC but may also cause severe side effects (6). For example, combinations of two chemo drugs are recommended to treat advanced GC but have more side effects, including increased chance of infection, fatigue and shortness of breath $(7,8)$. Thus, novel drug candidates that exert potent anti-GC effects are urgently required.

There is a well-established association between inflammation and cancer (9). In 1863, Virchow observed a 'lymphoreticular infiltrate' in the tumor site and proposed a potential association between inflammation and cancer (10). Over the past decades, it has become widely accepted that inflammation plays a key role in tumorigenesis and certain underlying molecular mechanisms have been described $(10,11)$. For example, inflammation may induce carcinogenesis by promoting angiogenesis and proliferation of tumor cells or causing DNA damage (12). Inflammation associated with tumor progression is caused by a variety of immune cells, including T lymphocytes, B lymphocytes, natural killer cells, dendritic cells, neutrophils and macrophages (13). Nuclear factor $(\mathrm{NF})-\kappa \mathrm{B}$ is one of the key factors driving inflammation in immune cells (14). In the tumor microenvironment, $\mathrm{NF}-\kappa \mathrm{B}$ is activated by various stimuli, including pro-inflammatory cytokines, cellular and environmental stresses, as well as DNA damage (15). Activated NF- $\kappa \mathrm{B}$ stimulates tumor growth and metastasis by promoting cell proliferation and tumor angiogenesis, thus preventing cell apoptosis and remodeling tumor metabolism $(14,15)$. Therefore, inhibition of $\mathrm{NF}-\kappa \mathrm{B}$ appears to be a promising approach to cancer treatment.

Bay11-7082 is a known inhibitor of $N F-\kappa B$ that acts by blocking tumor necrosis factor- $\alpha$-induced IкB phosphorylation (16). Previous studies have demonstrated that treatment with Bay11-7082 exerts antitumor effects on different types of cancer, including bladder, breast, esophageal and lung 
cancers (17-19). However, to the best of our knowledge, only a limited number of studies have investigated the antitumor activity of Bay11-7082 in GC. Thus, the present study aimed to investigate the antitumor effects of Bay11-7082 on GC and elucidate its underlying molecular mechanisms. Furthermore, the present study investigated whether the effects of Bay11-7082 are mediated via inhibition of GLI Family Zinc Finger 1 (Gli1), which acts as an oncogene in GC (20).

\section{Materials and methods}

Cell lines and cell culture. MKN45 cells were purchased from Fuheng Biotechnology Co., Ltd. (https://www.fudancell.com), while HGC cells were purchased from Procell Life Science \& Technology Co., Ltd. All cells were maintained in RPMI-1640 medium (Gibco; Thermo Fisher Scientific, Inc.) supplemented with $10 \%$ fetal bovine serum (FBS, Tianhang Biotechnology Co., Ltd., http://zjthsw.foodmate.net), $100 \mu \mathrm{g} / \mathrm{ml}$ streptomycin and $100 \mathrm{IU} / \mathrm{ml}$ penicillin (Beyotime Institute of Biotechnology), at $37^{\circ} \mathrm{C}$ with $5 \% \mathrm{CO}_{2}$.

MTT assay. The effect of Bay11-7082 on the proliferation of MKN45 and HGC27 cells was assessed via the MTT assay. Cells were seeded into 96 -well plates at a density of $5 \times 10^{4}$ cells/well and cultured overnight at $37^{\circ} \mathrm{C}$. Following incubation, different concentrations of Bay11-7082 (0.01, 0.10, $1.00,10.00$ and $20.00 \mu \mathrm{M}$ ) were added into each well and incubated for 24, 48 and $72 \mathrm{~h}$, respectively. Subsequently, MTT solution (Beyotime Institute of Biotechnology) was added into each well and incubated for $4 \mathrm{~h}$ at $37^{\circ} \mathrm{C}$. Following the MTT incubation, the purple formazan crystals were dissolved using dimethyl and cell proliferation was subsequently analyzed at a wavelength of $450 \mathrm{~nm}$.

The half-maximal inhibitory concentration $\left(\mathrm{IC}_{50}\right)$ values were calculated based on the percentage of cell proliferation (vehicle-treated cells were considered as $100 \%$ viable).

Wound healing assay. Following treatment with $10 \mathrm{nM}$ Bay11-7082 for $72 \mathrm{~h}$, the wound healing assay was performed. Briefly, HGC27 or MKN45 cells were incubated in serum-free medium in the presence of mitomycin (Sigma-Aldrich; Merck $\mathrm{KGaA}, 1 \mu \mathrm{g} / \mathrm{ml}$ ) for $1 \mathrm{~h}$ at $37^{\circ} \mathrm{C}$. Once the cells reached $90 \%$ confluence, the monolayers were scratched using $200 \mu \mathrm{l}$ pipette tips, and cells were washed with serum-free medium to remove cell debris. Subsequently, cells were cultured for another $24 \mathrm{~h}$ at $37^{\circ} \mathrm{C}$ and cell migration was observed under a confocal microscope (magnification, x100; Nikon 80i, Nikon Corporation).

Cell invasion. The cell invasion assay was performed using a 24-well Transwell chamber, which includes a membrane filter $(3.0 \mu \mathrm{m})$ and inserts coated with $200 \mathrm{mg} / \mathrm{ml}$ Matrigel and dried overnight at $37^{\circ} \mathrm{C}$ under sterile conditions. Cells $\left(1 \times 10^{4}\right)$ were plated in the upper chambers of Transwell plates in serum-free RPMI-1640 medium, while RPMI-1640 medium supplemented with $10 \%$ FBS was plated in the lower chambers. Following incubation for $24 \mathrm{~h}$ at $37^{\circ} \mathrm{C}$, the invasive cells were fixed with $4 \%$ polyoxymethylene at $25^{\circ} \mathrm{C}$ for $30 \mathrm{~min}$ and subsequently stained with crystal violet $(0.5 \% \mathrm{v} / \mathrm{v}$ in ethanol) at $25^{\circ} \mathrm{C}$ for $5 \mathrm{~min}$. Stained cells were counted using a confocal microscope (magnification, x200; Nikon 80i, Nikon Corporation).

Reverse transcription-quantitative (RT-q) PCR. The RNA extraction kit (BioTeke Corporation) was used to extract RNA from MKN45 and HGC27 cells, according to the manufacturer's instructions. RT kit and RNase inhibitor were purchased from BioTeke Corporation. The conditions for RT were as follows: $70^{\circ} \mathrm{C}$ for $10 \mathrm{~min}, 25^{\circ} \mathrm{C}$ for $10 \mathrm{~min}, 42^{\circ} \mathrm{C}$ for $50 \mathrm{~min}$ and $80^{\circ} \mathrm{C}$ for $10 \mathrm{~min}$. qPCR was subsequently performed using SYBR-Green Master Mix (Beijing Solarbio Science \& Technology Co., Ltd.). The primer sequences used for qPCR were designed by Wanlei Biotech Co., Ltd., (http://www. wanleibio.cn), and the melt curves were used to analyze the accuracy. The following primer sequences were used: Gli1 forward, 5'- TTCCTACCAGAGTCCCAAGT-3' and reverse, 5'-CCCTATGTGAAGCCCTATTT; p65 forward, 5'-GGG GACTACGACCTGAATG-3' and reverse, 5'-GGGCACGAT TGTCAAAGAT-3'; and $\beta$-actin forward, 5'-GGCACCCAG CACAATGAA-3' and reverse, 5'-TAGAAGCATTTGCGG TGG-3'. The following thermocycling conditions were used: $94^{\circ} \mathrm{C}$ for $5 \mathrm{~min}$, followed by 40 cycles at $94^{\circ} \mathrm{C}$ for $10 \mathrm{sec}, 60^{\circ} \mathrm{C}$ for $20 \mathrm{sec}$ and at $40^{\circ} \mathrm{C}$ for $1 \mathrm{~min} 30 \mathrm{sec}$. Relative expression levels were calculated using the $2^{-\Delta \Delta \mathrm{Cq}}$ method (21) and normalized to the internal reference gene GAPDH.

Western blotting. Total protein was extracted from MKN45 and HGC27 cells, as previously described (22). Briefly, a cold RIPA buffer (Wanlei Biotech Co., Ltd.) containing protease inhibitor was used to lyse the cells. Subsequently, the extraction buffer was centrifuged at $13,000 \mathrm{x}$ g for $15 \mathrm{~min}$ at $4^{\circ} \mathrm{C}$ to remove the sample debris and other insoluble materials. Total protein was quantified via the BCA protein assay (Biosharp Life Sciences) (23) and $40 \mu \mathrm{g}$ protein/lane was separated by $10 \%$ SDS-PAGE. The separated proteins were subsequently transferred onto PVDF membranes and blocked with 5\% non-fat milk at room temperature for $2 \mathrm{~h}$. The membranes were incubated with primary antibodies against NF-кB p65 (1:500; cat. no. WL01980), phosphorylated (p)-NF- $\mathrm{B}$ p65 (1:500; cat. no. WL02169) and Gli1 (1:3,000; cat. no. 66905-1-lg) overnight at $4^{\circ} \mathrm{C}$ (all purchased from Wanlei Biotech Co., Ltd.). Following the primary incubation, membranes were incubated with goat anti-rabbit secondary IgG antibodies conjugated with horseradish peroxidase (1:5,000; cat. no. WLA023) at $37^{\circ} \mathrm{C}$ for $45 \mathrm{~min}$. $\beta$-actin was used as the internal control (1:1,000, WL01845). The Biorad Gel Imaging System (Bio-Rad Laboratories, Inc.) was used to detect the expression levels of the target genes.

Statistical analysis. Statistical analysis was performed using GraphPad Prism 8 software (GraphPad Software, Inc.). Data are presented as the mean \pm standard deviation. Unpaired Student's t-test was used to compare differences between the control and Bay11-7082-treated groups. $\mathrm{P}<0.05$ was considered to indicate a statistically significant difference.

\section{Results}

Cytotoxic effects of Bay11-7082 on HGC27 and MKN45 cells. The cytotoxic effects of Bay11-7082 on HGC27 and MKN45 

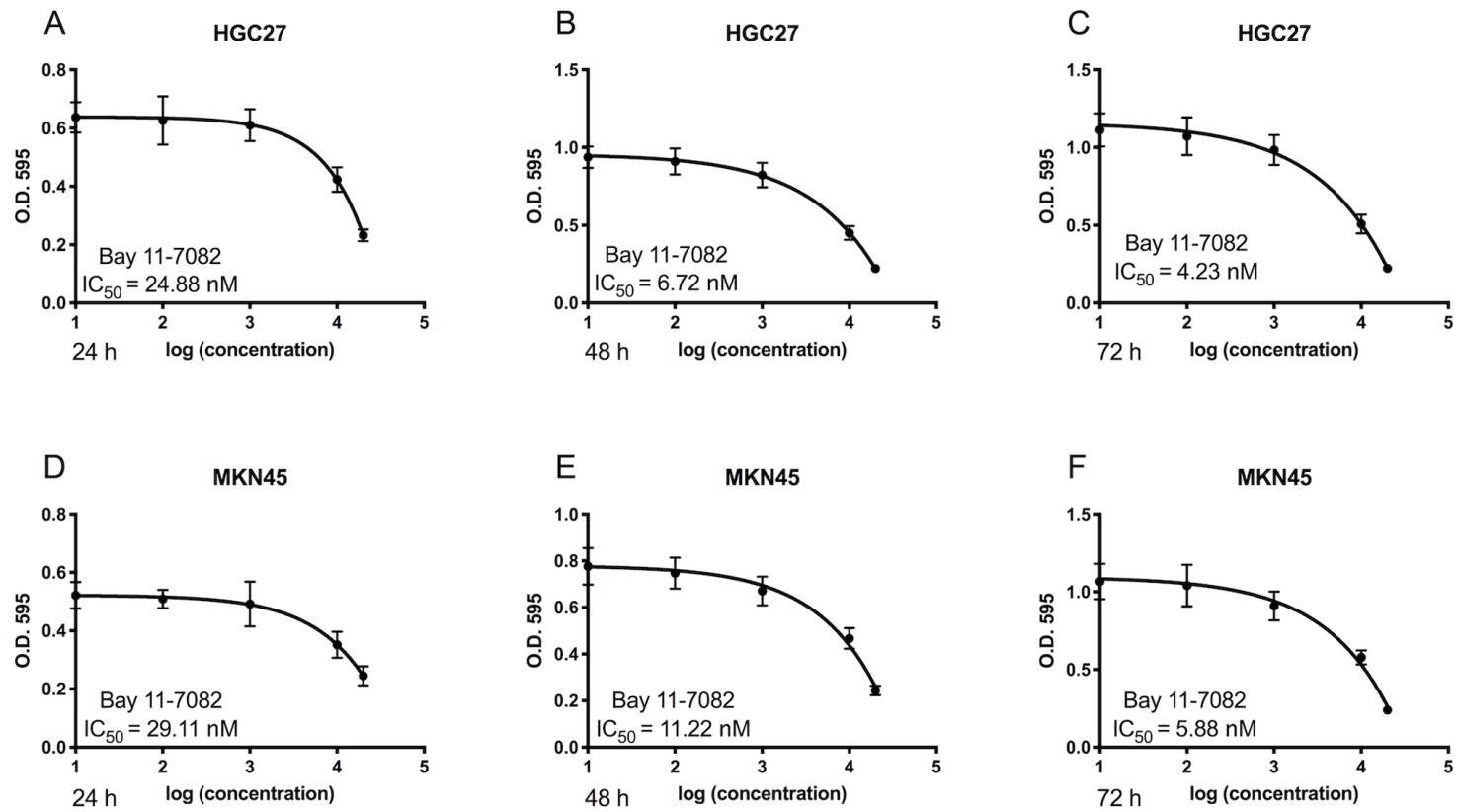

Figure 1. Bay11-7082 inhibits the proliferation of HGC27 and MKN45 cells. (A-C) HGC27 cells were treated with different concentrations of Bay11-7082 for 24, 48 and $72 \mathrm{~h}$, and cell proliferation was assessed via the MTT assay. (D-F) MKN45 cells were treated with different concentrations of Bay11-7082 for 24, 48 and $72 \mathrm{~h}$, and cell proliferation was assessed via the MTT assay. Data are presented as the mean \pm standard deviation $(\mathrm{n}=3)$. $\mathrm{IC}_{50}$, half-maximal inhibitory concentration; OD, optical density.

cells were first determined. As presented in Fig. 1, treatment with Bay11-7082 markedly suppressed the proliferation of HGC27 and MKN45 cells. Furthermore, Bay11-7082 inhibited the proliferation of GC cells in dose- and time-dependent manners. The $\mathrm{IC}_{50}$ values of Bay11-7082 in HGC27 cells at 24, 48 and $72 \mathrm{~h}$ were $24.88,6.72$ and $4.23 \mathrm{nM}$, respectively (Fig. 1A-C). The $\mathrm{IC}_{50}$ values of Bay11-7082 in MKN45 cells at 24,48 and $72 \mathrm{~h}$ were $29.11,11.22$ and $5.88 \mathrm{nM}$ (Fig. 1D-F). Based on these results, $10 \mathrm{nM}$ Bay11-7082 was selected for further mechanistic studies.

Bay11-7082 suppresses the migratory and invasive abilities of HGC27 and MKN45 cells. The effect of Bay11-7082 on the migration of HGC27 and MKN45 cells was assessed via the wound healing assay. The results demonstrated that treatment with Bay11-7082 significantly decreased the migratory ability of HGC27 cells compared with the control group (P<0.01; Fig. 2A and B). Similarly, treatment with Bay11-7082 significantly decreased the migratory ability of MKN45 cells compared with the control group ( $\mathrm{P}<0.01$; Fig. $2 \mathrm{C}$ and $\mathrm{D})$.

The effect of Bay11-7082 on HGC27 and MKN45 cell invasion was also determined. As presented in Fig. 3A, treatment with Bay11-7082 significantly decreased the number of invasive HGC27 cells compared with the control group $(\mathrm{P}<0.0001)$. Similarly, treatment with Bay11-7082 significantly decreased the numbers of invasive MKN45 cells compared with the control group $(\mathrm{P}<0.001$; Fig. 3B).

Bay11-7082 inhibits Gli1 mRNA and protein expression levels in HGC27 and MKN45 cells. The molecular mechanisms underlying the inhibitory effects of Bay11-7082 on HGC27 and MKN45 cells were investigated. First, the effects of Bay11-7082 on Gli1 and p65 mRNA expression levels were assessed. Notably, Bay11-7082 had no inhibitory effect on p65 mRNA expression (Fig. 4A and C). Thus, it was inferred that the inhibitory effect of Bay11-7082 on NF- $\mathrm{BB}$ was exerted at the post-transcriptional level. As expected, the results demonstrated that treatment with Bay11-7082 decreased the protein expression levels of p-NF-кB p65 in both HGC27 and MKN45 cells (Fig. 4E).

The effect of Bay11-7082 on Gli1 mRNA expression was investigated. Notably, the results demonstrated that treatment with Bay11-7082 significantly inhibited Gli1 mRNA expression in HGC27 cells compared with the control group $(\mathrm{P}<0.001$; Fig. 4B). Similarly, treatment with Bay11-7082 significantly suppressed Gli1 mRNA expression in MKN45 cells compared with the control group $(\mathrm{P}<0.0001$; Fig. 4D). The effect of Bay11-7082 on Gli1 protein expression was also investigated. The results demonstrated that treatment with Bay11-7082 significantly suppressed Gli1 protein expression compared with the control group (Fig. 4E).

\section{Discussion}

The present study aimed to investigate the effects of Bay11-7082, a known inhibitor of NF-кB (24), on the GC cell lines, HGC27 and MKN45. The results demonstrated that treatment with Bay11-7082 significantly inhibited the proliferation, migration and invasion of HGC27 and MKN45 cells. Notably, in addition to its inhibitory effects on p-NF- $\mathrm{KB}$ p65, Bay11-7082 also exerted inhibitory effects on Gli1, which is a well-known glioma-associated oncogene (20).

$\mathrm{NF}-\mathrm{\kappa B}$ is activated by various stimuli, including pro-inflammatory cytokines, cellular and environmental stressors, and DNA damage in the tumor tissues (12). Activated NF- $\mathrm{KB}$ stimulates tumor growth and metastasis through a series of 
A

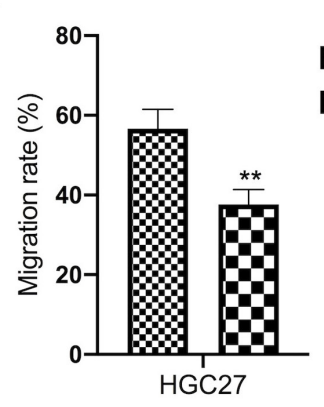

C

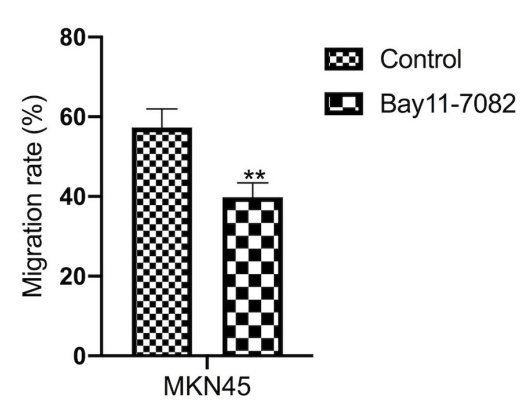

Control

므 Bay11-7082
B

$\mathrm{Oh}$

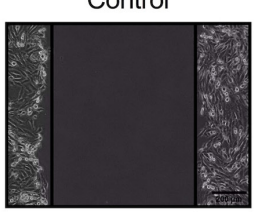

Bay11-7082

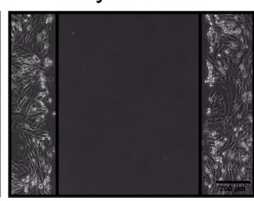

$24 \mathrm{~h}$
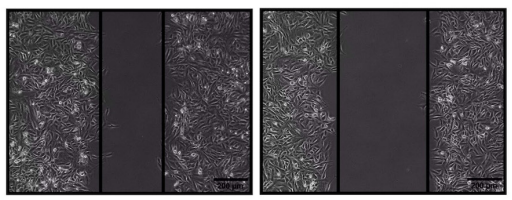

D

Control

$\mathrm{oh}$

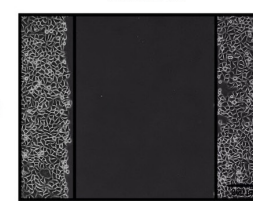

Bay11-7082

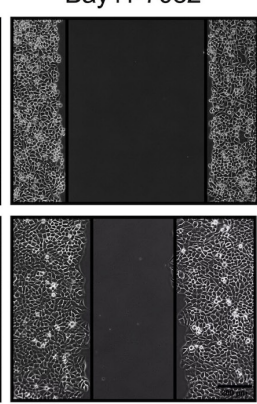

Figure 2. Bay11-7082 inhibits the migration of HGC27 and MKN45 cells. The wound healing assay was performed to assess the migratory ability of (A and B) HGC27 and (C and D) MKN45 cells following treatment with $10 \mathrm{nM}$ Bay11-7082 for $24 \mathrm{~h}$. Data are presented as the mean \pm standard deviation (n=3). ${ }^{* *} \mathrm{P}<0.01$ vs. control.

A

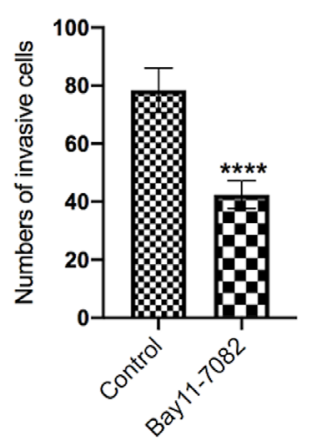

B

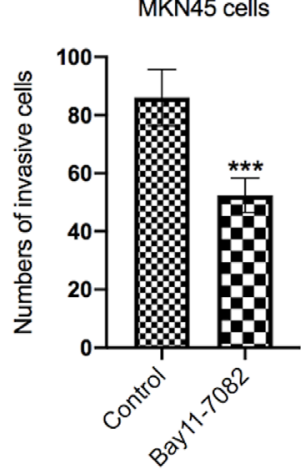

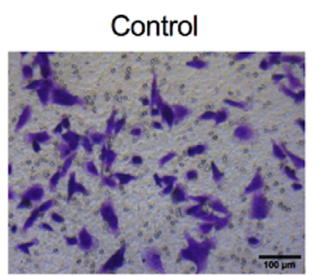

Bay11-7082

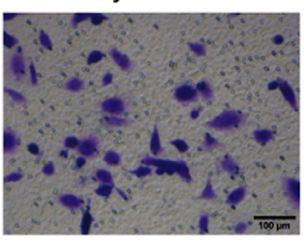

Control

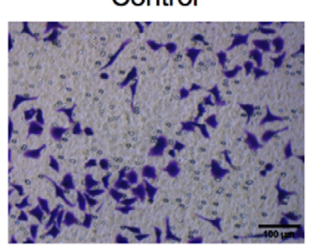

Bay11-7082

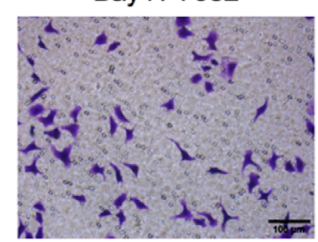

Figure 3. Bay11-7082 inhibits the invasive ability of HGC27 and MKN45 cells. (A) The Transwell assay was performed to assess the invasive ability of (A) HGC27 and (B) MKN45 cells following treatment with $10 \mathrm{nM}$ Bay11-7082 for $24 \mathrm{~h}$. Data are presented as the mean \pm standard deviation (n=3). ${ }^{* * * *} \mathrm{P}<0.001$, ${ }^{* * * * *} \mathrm{P}<0.0001$ vs. control.

processes, including: i) Promoting cell proliferation and tumor angiogenesis, ii) preventing cell apoptosis, and iii) remodeling the tumor metabolism (15). Thus, inhibition of NF- $\kappa \mathrm{B}$ appears to be a promising approach to cancer treatment. 
A

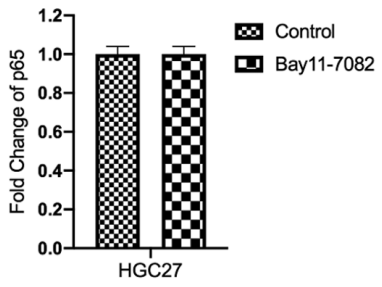

C

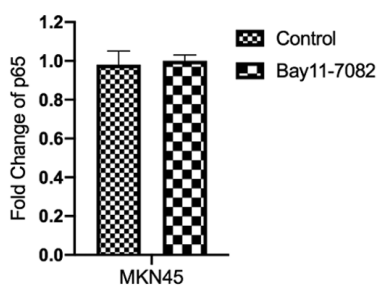

B

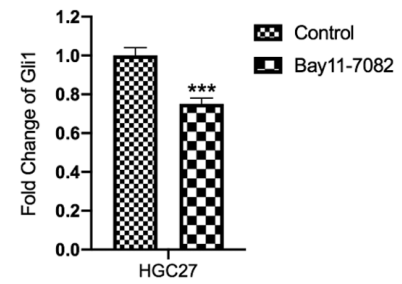

D

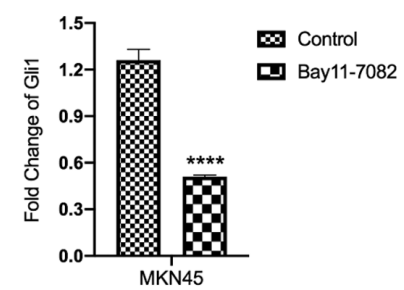

E

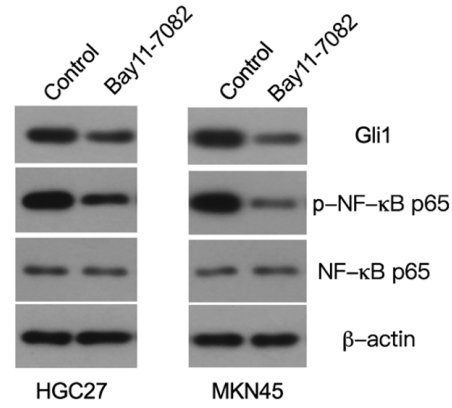

Figure 4. Bay11-7082 inhibits Gli1 mRNA and protein expression levels in HGC27 and MKN45 cells. (A-D) Reverse transcription-quantitative PCR analysis was performed to detect the mRNA expression levels of p65 and Gli1 in HGC27 and MKN45 cells. (E) Western blot analysis was performed to detect the

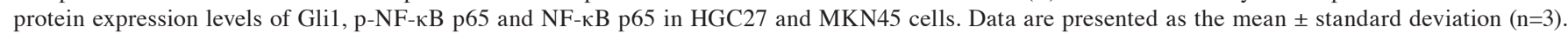
${ }^{* * *} \mathrm{P}<0.001,{ }^{* * * *} \mathrm{P}<0.0001$ vs. control. Gli1, GLIFamily Zinc Finger 1.

Bay11-7082 act as an inhibitor of NF-kB (16). Previous studies have demonstrated that Bay11-7082 exerts broad inhibitory effects against prostate, esophageal, lung and colorectal cancers and lymphoma (25-29). For example, Bay11-7082 has been reported to prevent tumor growth at the primary site, as well as leukemic cell infiltration in various organs of NOG mice (24). Notably, Bay11-7082 does not exert any severe adverse effects on mice during the treatment period (30). In addition, Bay11-7082 has been used in the treatment of several other experimental diseases, such as systemic lupus erythematosus, stress-induced gastric inflammatory damage, diabetic neuropathy and endothelin-induced lung edema (31-34). These studies have demonstrated that apart from inhibiting NF- $\mathrm{KB}$, Bay11-7082 also exerts diverse effects on other signaling pathways. For example, Zhang et al (17) demonstrated that the antitumor effect of Bay11-7082 on bladder cancer is associated with its modulation of Snail signaling pathways. In addition, Zhang et al (18) reported that Bay11-7082 also regulates apoptosis-related genes, including B-cell lymphoma (Bcl)-2 and $\mathrm{Bcl}-\mathrm{xL}$, and the expression of matrix metalloproteinases in lung cancers. However, few studies have focused on the antitumor effects of Bay11-7082 in GC $(17,24)$. In addition, Bay11-7082 has not undergone clinical development.

To the best of our knowledge, the present study was the first to investigate the effects of Bay11-7082 on two GC cell lines, namely HGC27 and MKN45, which are commonly used in pre-clinical studies $(35,36)$. The HGC27 cell line was derived from a lymph node metastasis of undifferentiated GC (37), while MKN45 is a poorly differentiated human gastric adenocarcinoma cell line, which was found to be moderately metastatic (38). In the present study, parallel studies were performed on both GC cell lines to determine the effects of Bay11-7082 in GC. The results demonstrated that treatment with Bay11-7082 significantly inhibited the proliferation, migration and invasion of $\mathrm{HGC} 27$ and MKN45 cells. Increasing evidence suggest that there is a complex interplay between NF-kB and Sonic hedgehog (SHH) (39). Cai et al (40) discovered that hedgehog signaling regulates NF- $\kappa \mathrm{B}$ through the classical pathway, SHH/PTCH1/SMO/Gli1, in multiple myeloma cells. Notably, Wei et al (41) reported that NF-кB and Gli1 form a positive feedback loop in esophageal cell lines, whereas inhibition of either NF- $\mathrm{\kappa B}$ or Gli1 inhibits cell migration, invasion and proliferation. The results of the present study demonstrated that Bay11-7082, in addition to inhibiting $\mathrm{NF}-\kappa \mathrm{B}$, also regulated Gli1 expression in the HGC27 and MKN45 cells, indicating a crosstalk between NF- $\mathrm{KB}$ and Gli1. These results support the hypothesis that Bay11-7082 may be used as a novel therapeutic method for the treatment of GC. However, in vivo studies are required to further elucidate the antitumor activity of Bay11-7082 in GC. In addition, further studies are required to confirm the association between NF- $\mathrm{\kappa B}$ and SHH in GC to support the clinical use of Bay11-7082 for the treatment of GC.

Hedgehog/Gli signaling recently attracted the attention of oncologists due to its widespread oncogenic activity in a variety of human malignancies $(42,43)$. Hedgehog/Gli signaling has been reported to be associated with cancer cell proliferation, metastasis, angiogenesis and self-renewal, making this signaling pathway a promising treatment target (44). In addition, NF- $\mathrm{kB}$ and the hedgehog/Gli signaling pathway has been implicated in the complex network of diverse molecular mechanisms leading to GC (45). The activation process of the human hedgehog pathway is initiated by the ligand of the hedgehog pathway, SHH, which results in entry of the nuclear factor Gli family proteins into the nucleus and initiates the regulation of downstream target genes (46). The Gli family includes three transcription factors, Gli1, Gli2 and Gli3. Gli1 is the only transcriptional activator, whereas Gli2 and Gli3 act as either positive or negative regulators (47). Thus, Gli1 expression leads to a positive feedback loop, and it acts as a constitutive activator (48).

In most cases, overexpression of Gli1 is considered a symbol of hedgehog signaling pathway activation (49). Thus, the present study aimed to investigate the effects of NF-кB inhibition on the hedgehog/Gli signaling pathway. The effect 
of Bay11-7082 on hedgehog gene expression was elucidated by assessing Gli1 mRNA and protein expression levels in the hedgehog signaling pathway. Notably, the results demonstrated that treatment with Bay11-7082 significantly decreased Gli1 mRNA and protein expression levels in HGC27 and MKN45 cells compared with the control group. Taken together, these results suggest that inhibition of $N F-\kappa B$ also affects the hedgehog/Gli signaling pathway. However, to elucidate the association between the effect of Bay11-7082 and the hedgehog pathway, SHH expression must also be investigated in prospective studies.

In conclusion, the present study demonstrated that treatment with Bay11-7082 significantly inhibited the proliferation, migration and invasion of HGC27 and MKN45 cells. Furthermore, the mechanistic studies revealed that Bay11-7082 exerted its anticancer effects in part by regulating NF- $\mathrm{KB}$ and Gli1.

\section{Acknowledgements}

The authors of the present study would like to thank Dr Syed Fayaz Hashmi (College of Pharmacy, University of Rhode Island) for critically assessing the manuscript.

\section{Funding}

The present study was largely supported by the financial support of the Science and Technology Development Project (grant no. SYSD2020167) Funded by Science and Technology Bureau of Suzhou City.

\section{Availability of data and materials}

The datasets used and/or analyzed during the present study are available from the corresponding author upon reasonable request.

\section{Authors' contributions}

YY and HQ performed most of the experiments, analyzed the data and drafted the initial manuscript. TZ and YC were responsible for the experimental design and drafting of the initial manuscript. YY and HQ confirmed the authenticity of all the raw data. All authors have read and approved the final version of the manuscript.

\section{Ethics approval and consent to participate}

Not applicable.

\section{Patient consent for publication}

Not applicable.

\section{Competing interests}

The authors declare that they have no competing interests.

\section{References}

1. Rawla P and Barsouk A: Epidemiology of gastric cancer: Global trends, risk factors and prevention. Prz Gastroenterol 14: 26-38, 2019.
2. Machlowska J, Baj J, Sitarz M, Maciejewski R and Sitarz R: Gastric Cancer: Epidemiology, risk factors, classification, genomic characteristics and treatment strategies. Int $\mathrm{J}$ Mol Sci 21: 4012, 2020

3. Balar AV, Galsky MD, Rosenberg JE, Powles T, Petrylak DP, Bellmunt J, Loriot Y, Necchi A, Hoffman-Censits J, Perez-Gracia JL, et al; IMvigor210 Study Group: Atezolizumab as first-line treatment in cisplatin-ineligible patients with locally advanced and metastatic urothelial carcinoma: A single-arm, multicentre, phase 2 trial. Lancet 389: 67-76, 2017.

4. Winawer SJ: Gastric cancer: Worldwide burden and prevention opportunities. Chin J Dig Dis 6: 107-109, 2005.

5. Ilson DH: Advances in the treatment of gastric cancer. Curr Opin Gastroenterol 33: 473-476, 2017.

6. Hess LM, Michael D, Mytelka DS, Beyrer J, Liepa AM and Nicol S: Chemotherapy treatment patterns, costs, and outcomes of patients with gastric cancer in the United States: A retrospective analysis of electronic medical record (EMR) and administrative claims data. Gastric Cancer 19: 607-615, 2016.

7. Lordick F and Siewert JR: Recent advances in multimodal treatment for gastric cancer: A review. Gastric Cancer 8: 78-85, 2005.

8. Zali H, Rezaei-Tavirani M and Azodi M: Gastric cancer: Prevention, risk factors and treatment. Gastroenterol Hepatol Bed Bench 4: 175-185, 2011.

9. Liccardi G and Pentimalli F: Cancer, immunity and inflammation. Report from the CDD Cambridge Conferences 2018 and 2019. Cell Death Dis 10: 798, 2019.

10. Grivennikov SI, Greten FR and Karin M: Immunity, inflammation, and cancer. Cell 140: 883-899, 2010.

11. Diakos CI, Charles KA, McMillan DC and Clarke SJ: Cancer-related inflammation and treatment effectiveness. Lancet Oncol 15: e493-e503, 2014.

12. Kawanishi S, Ohnishi S, Ma N, Hiraku Y and Murata M: Crosstalk between DNA Damage and Inflammation in the Multiple Steps of Carcinogenesis. Int J Mol Sci 18: 1808, 2017.

13. Zamarron BF and Chen W: Dual roles of immune cells and their factors in cancer development and progression. Int J Biol Sci 7: 651-658, 2011.

14. Del Prete A, Allavena P, Santoro G, Fumarulo R, Corsi MM and Mantovani A: Molecular pathways in cancer-related inflammation. Biochem Med (Zagreb) 21: 264-275, 2011.

15. Dolcet X, Llobet D, Pallares J and Matias-Guiu X: NF-kB in development and progression of human cancer. Virchows Arch 446: 475-482, 2005.

16. Zhao J, Zhang H, Huang Y, Wang H, Wang S, Zhao C, Liang Y and Yang N: Bay11-7082 attenuates murine lupus nephritis via inhibiting NLRP3 inflammasome and NF- $\kappa \mathrm{B}$ activation. Int Immunopharmacol 17: 116-122, 2013.

17. Zhang Q, Mao Z and Sun J: NF- $\kappa$ B inhibitor, BAY11-7082, suppresses M2 tumor-associated macrophage induced EMT potential via miR-30a/NF- $\kappa \mathrm{B} /$ Snail signaling in bladder cancer cells. Gene 710: 91-97, 2019.

18. Zhang L, Xie J, Gan R, Wu Z, Luo H, Chen X, Lu Y, Wu L and Zheng D: Synergistic inhibition of lung cancer cells by EGCG and NF- $\mathrm{kB}$ inhibitor BAY11-7082. J Cancer 10: 6543-6556, 2019.

19. Viola K, Kopf S, Huttary N, Vonach C, Kretschy N, Teichmann M, Giessrigl B, Raab I, Stary S, Krieger S, et al: Bay11-7082 inhibits the disintegration of the lymphendothelial barrier triggered by MCF-7 breast cancer spheroids; the role of ICAM-1 and adhesion. Br J Cancer 108: 564-569, 2013.

20. Tang CT, Liang Q, Yang L, Lin XL, Wu S, Chen Y, Zhang XT, Gao YJ and Ge ZZ: RAB31 Targeted by miR-30c-2-3p regulates the GLI1 signaling pathway, affecting gastric cancer cell proliferation and apoptosis. Front Oncol 8: 554, 2018.

21. Livak KJ and Schmittgen TD: Analysis of relative gene expression data using real-time quantitative PCR and the 2(-Delta Delta C(T)) Method. Methods 25: 402-408, 2001.

22. Yu M, Ren L, Liang F, Zhang Y, Jiang L, Ma W, Li C, Li X and Ye X: Effect of epiberberine from Coptis chinensis Franch on inhibition of tumor growth in MKN-45 xenograft mice. Phytomedicine 76: 153216, 2020.

23. Yang $\mathrm{H}$, Wang J, Fan JH, Zhang YQ, Zhao JX, Dai XJ, Liu Q, Shen YJ, Liu C, Sun WD, et al: Ilexgenin A exerts anti-inflammation and anti-angiogenesis effects through inhibition of STAT3 and PI3K pathways and exhibits synergistic effects with Sorafenib on hepatoma growth. Toxicol Appl Pharmacol 315: 90-101, 2017. 
24. García MG, Alaniz L, Lopes EC, Blanco G, Hajos SE and Alvarez E: Inhibition of NF-kappaB activity by BAY 11-7082 increases apoptosis in multidrug resistant leukemic T-cell lines. Leuk Res 29: 1425-1434, 2005.

25. Zheng X, Chang RL, Cui XX, Avila G, Huang MT, Liu Y, Kong AN, Rabson AB and Conney AH: Inhibition of NF-kappaB by (E)3-[(4-methylphenyl)-sulfonyl]-2-propenenitrile (BAY11-7082; BAY) is associated with enhanced 12-O-tetradecanoylphorbol-13-acetate-induced growth suppression and apoptosis in human prostate cancer PC-3 cells Int J Oncol 32: 257-264, 2008.

26. Li B, Li YY, Tsao SW and Cheung AL: Targeting NF-kappaB signaling pathway suppresses tumor growth, angiogenesis, and metastasis of human esophageal cancer. Mol Cancer Ther 8: 2635-2644, 2009.

27. Xue W, Meylan E, Oliver TG, Feldser DM, Winslow MM, Bronson R and Jacks T: Response and resistance to NF- $\kappa$ B inhibitors in mouse models of lung adenocarcinoma. Cancer Discov 1: 236-247, 2011.

28. Scaife CL, Kuang J, Wills JC, Trowbridge DB, Gray P, Manning BM, Eichwald EJ, Daynes RA and Kuwada SK: Nuclear factor kappaB inhibitors induce adhesion-dependent colon cancer apoptosis: Implications for metastasis. Cancer Res 62: 6870-6878, 2002

29. Keller SA, Hernandez-Hopkins D, Vider J, Ponomarev V, Hyjek E, Schattner EJ and Cesarman E: NF-kappaB is essential for the progression of KSHV- and EBV-infected lymphomas in vivo. Blood 107: 3295-3302, 2006.

30. Dewan MZ, Terashima K, Taruishi M, Hasegawa H, Ito M Tanaka Y, Mori N, Sata T, Koyanagi Y, Maeda M, et al: Rapid tumor formation of human T-cell leukemia virus type 1-infected cell lines in novel NOD-SCID/gammac(null) mice: Suppression by an inhibitor against NF-kappaB. J Virol 77: 5286-5294, 2003.

31. Miyamoto R,Ito T,Nomura S, Amakawa R, Amuro H,Katashiba Y, Ogata M, Murakami N, Shimamoto K, Yamazaki C, et al Inhibitor of IkappaB kinase activity, BAY 11-7082, interferes with interferon regulatory factor 7 nuclear translocation and type I interferon production by plasmacytoid dendritic cells. Arthritis Res Ther 12: R87, 2010

32. Jia YT, Ma B, Wei W, Xu Y, Wang Y, Tang HT and Xia ZF: Sustained activation of nuclear factor-kappaB by reactive oxygen species is involved in the pathogenesis of stress-induced gastric damage in rats. Crit Care Med 35: 1582-1591, 2007.

33. Kumar A, Negi G and Sharma SS: Suppression of NF- $\kappa$ B and $\mathrm{NF}-\kappa \mathrm{B}$ regulated oxidative stress and neuroinflammation by BAY 11-7082 (IкB phosphorylation inhibitor) in experimental diabetic neuropathy. Biochimie 94: 1158-1165, 2012.

34. Piechota A and Goraca A: Influence of nuclear factor- $\kappa$ B inhibition on endothelin-1 induced lung edema and oxidative stress in rats. J Physiol Pharmacol 62: 183-188, 2011.

35. Terzioğlu G, Türksoy Ö and Bayrak ÖF: Identification of An mtDNA Setpoint Associated with Highest Levels of CD44 Positivity and Chemoresistance in HGC-27 and MKN-45 Gastric Cancer Cell Lines. Cell J 20: 312-317, 2018.
36. Peng Y, Liu YM, Li LC, Wang LL and Wu XL: MicroRNA-503 inhibits gastric cancer cell grow th and epithelial-to-mesenchymal transition. Oncol Lett 7: 1233-1238, 2014.

37. Akagi T and Kimoto T: Human cell line (HGC-27) derived from the metastatic lymph node of gastric cancer. Acta Med Okayama 30: 215-219, 1976.

38. Busuttil RA, Liu DS, Di Costanzo N, Schröder J, Mitchell C and Boussioutas A: An orthotopic mouse model of gastric cancer invasion and metastasis. Sci Rep 8: 825, 2018

39. Kasperczyk H, Baumann B, Debatin KM and Fulda S: Characterization of sonic hedgehog as a novel NF-kappaB target gene that promotes NF-kappaB-mediated apoptosis resistance and tumor growth in vivo. FASEB J 23: 21-33, 2009.

40. Cai K, Na W, Guo M, Xu R, Wang X, Qin Y, Wu Y, Jiang J and Huang $\mathrm{H}$ : Targeting the cross-talk between the hedgehog and $\mathrm{NF}-\kappa \mathrm{B}$ signaling pathways in multiple myeloma. Leuk Lymphoma 60: 772-781, 2019.

41. Wei L, Yan N, Sun L, Bao C and Li D: Interplay between the $\mathrm{NF} \kappa \mathrm{B}$ and hedgehog signaling pathways predicts prognosis in esophageal squamous cell carcinoma following neoadjuvant chemoradiotherapy. Int J Mol Med 41: 2961-2967, 2018.

42. Chen M, Carkner R and Buttyan R: The hedgehog/Gli signaling paradigm in prostate cancer. Expert Rev Endocrinol Metab 6: 453-467, 2011.

43. Xie H, Paradise BD, Ma WW and Fernandez-Zapico ME: Recent Advances in the Clinical Targeting of Hedgehog/GLI Signaling in Cancer. Cells 8: 394, 2019.

44. Wessler S, Krisch LM, Elmer DP and Aberger F: From inflammation to gastric cancer - the importance of Hedgehog/GLI signaling in Helicobacter pylori-induced chronic inflammatory and neoplastic diseases. Cell Commun Signal 15: 15, 2017.

45. Wu WK, Cho CH, Lee CW, Fan D, Wu K, Yu J and Sung JJ: Dysregulation of cellular signaling in gastric cancer. Cancer Lett 295: 144-153, 2010.

46. Kasper M, Regl G, Frischauf AM and Aberger F: GLI transcription factors: Mediators of oncogenic Hedgehog signalling. Eur J Cancer 42: 437-445, 2006.

47. Sasaki H, Nishizaki Y, Hui C, Nakafuku M and Kondoh H: Regulation of Gli2 and Gli3 activities by an amino-terminal repression domain: Implication of Gli2 and Gli3 as primary mediators of Shh signaling. Development 126: 3915-3924, 1999.

48. Lauth M and Toftgărd R: Non-canonical activation of GLI transcription factors: Implications for targeted anti-cancer therapy. Cell Cycle 6: 2458-2463, 2007.

49. Damhofer H, Veenstra VL, Tol JA, van Laarhoven HW, Medema JP and Bijlsma MF: Blocking Hedgehog release from pancreatic cancer cells increases paracrine signaling potency. J Cell Sci 128: 129-139, 2015

This work is licensed under a Creative Commons Attribution-NonCommercial-NoDerivatives 4.0 International (CC BY-NC-ND 4.0) License. 